tera: Noctuidae) during pod or seed development. J. Econ. Entomol. 89:525-535.

Young, L.D., and E.E. Hartwig. 1988. Selective pressure on soybean cyst nematode from soybean cropping sequences. Crop Sci. 28 845-847.
Young, L.D., E.E. Hartwig, S.C. Anand, and D. Widick. 1986. Responses of soybeans and soybean cyst nematodes to cropping sequences. Plant Dis. 70:787-791.

\title{
Predicting Rice Yield Losses Caused by Multispecies Weed Competition
}

\author{
Jaime A. Florez, Albert J. Fischer,* Hector Ramirez, and Miryam C. Duque
}

\begin{abstract}
Monoculture of irrigated rice (Oryza sativa L.) in Latin America has led to serious weed problems and intensive herbicide use. Yield loss prediction enables the economic analysis of weed control, providing a basis for strategic use of herbicides and diversified weed management, but site differences restrict predictions to the environments for which the models are calibrated. We developed an algorithm for predicting rice yield losses based on early assessments of multispecies weed infestations emerging in successive flushes within variable crop stands. Rice was drill-seeded near Palmira, Colombia, at 75, 150, 200, 250 , and $300 \mathrm{~kg} \mathrm{ha}^{-1}$, and grown under nonflood intermittent irrigation for two growing seasons. Five common weeds were allowed to emerge at 15,24 , and 30 days after rice emergence (DAE), when farmers usually decide about early, intermediate, and late herbicide applications. Yield losses were predicted using hyperbolic models with independent variables describing the mixed-weed infestations in terms of density (no. of plants $\mathrm{m}^{-2}$ ), leaf area index, dry matter $\mathrm{m}^{-2}$, relative density [weed/(weed + rice)], relative leaf area (RLA), and a visual estimate of relative ground cover $\left(\mathbf{R C}_{\mathrm{v}}\right)$. With early weed emergence (15 DAE), weed density accounted poorly $\left(r^{2}=0.77\right)$ for yield loss. Regression fits improved when RLA $\left(r^{2}=0.86\right)$ and $\operatorname{RC}_{v}\left(r^{2}=0.90\right)$ were used as independent variables to describe weed infestations in terms of the light apportionment between rice and weed canopies. Measured in terms of $\mathbf{R C}_{v}$, late-emerging ( 24 and $30 \mathrm{DAE}$ ) weeds had lower effects on yield loss variability $\left(r^{2}=0.69\right.$ and 0.59 , respectively). Although subjective, $\mathbf{R C}_{\mathrm{v}}$ is easier to estimate than RLA, and was the best single variable to describe the competitiveness of a mixedweed infestation. An additional variable was needed only when yield losses were predicted from weed density. Predictions based on RLA were further improved (by 36\%) when each species' RLA was measured separately and the model was extended for additive effects of all species. Yield loss predictions using empirical equations cannot be extrapolated widely across different locations; however, these data suggest that meaningful independent variables can strengthen the usefulness of hyperbolic equations for predicting rice yield losses over a range of situations, such as mixtures of weed species at various densities and times of emergence, and different rice seeding rates.
\end{abstract}

$\mathrm{R}^{\mathrm{s}}$ ICE IN Latin America occupies 6.5 million hectares, and 20.5 million tonnes of rice are produced in irrigated systems (FAO, 1997). In tropical Latin America, where two or more rice harvests are obtained each year, weeds are a serious constraint to rice production. Serious weed problems have resulted from continuous

A.J. Fischer, Dep. of Vegetable Crops, Univ. of California, Davis, CA 95616-8746; J.A. Florez, H. Ramirez, and M.C. Duque, Rice Program, CIAT, A.A. 6713, Cali, Colombia (ciat@cgiar.org). Contribution of CIAT. Received 1 Nov. 1997. *Corresponding author (ajfischer@vegmail.ucdavis.edu).

Published in Agron. J. 91:87-92 (1999). rice cropping, such as red rice (a weedy Oryza sativa L.) and the difficult-to-control junglerice [Echinochloa colona (L.) Link]. The situation is often aggravated when discontinuous irrigation cannot maintain a permanent and weed-suppressive flood. This allows weeds to emerge in successive flushes, prompting farmers to use herbicides two to four times during the growing season. Thus, with rice grown almost all year round, and a large number of chemicals available, the herbicide load on rice soils and waterways must be large.

A more recent problem resulting from the repeated use of herbicides has been the development of herbicide resistance in populations of relevant weeds of rice. Propanil [ $\mathrm{N}$-( $3^{\prime}, 4^{\prime}$-dichlorophenyl) propionamide]-resistant biotypes of junglerice abound in rice areas of Colombia and Costa Rica (Fischer et al., 1993; Valverde, 1996). Increasingly frequent and complex herbicide use to control herbicide-resistant weed biotypes has led to the development of multiple resistance (Valverde, 1996). Herbicides, although a much-needed tool, cost Latin American farmers \$218 million (U.S. dollars) yearly. Early weed control is almost invariably required to manage the generalized weed infestations resulting from the heavy seed rain in most tropical rice fields. The need for herbicide applications beyond $30 \mathrm{~d}$ after rice emergence (DAE) must be clearly justified. Thus, objective decisions on herbicide use, based on cost-benefit analysis, are needed to address high production costs, herbicide resistance, and other possible effects of herbicide overuse. Such analysis requires an objective method for predicting yield losses based upon early assessments of the weed population (Kropff, 1988).

Advisory systems based on short- and long-term economic analysis have been developed for various crops to assist in the selection of weed control alternatives (Coble and Mortensen, 1992; Lybecker et al., 1991; Wilkerson et al., 1991; Kwon et al., 1995). Such advisory packages must rely on accurate equations to predict crop losses from weed competition. These simple empirical functions can be more widely adopted than more complex ecophysiological competition models. Such mechanistic models are helpful in scientific research, because yield losses can be predicted for different weed and crop growing scenarios (Kropff, 1993), but their parameters can be difficult to estimate, leading to inaccuracies in the final predictions (Kropff and Spitters, 1991). Instead, easy-to-estimate rectangular hyperbolic functions have

Abbreviations: DAE, days after [rice] emergence; $\mathrm{RC}_{\mathrm{v}}$, relative ground cover, visual estimation; RLA, relative leaf area. 
been widely and successfully used to describe the effects of weed density (no. plants per unit area) on crop yield (Cousens, 1985a, 1985b; Kropff and Lotz, 1993; Coble and Mortensen, 1992).

Relationships to predict yield losses from weed competition have often considered a single weed species emerging at one time, within a uniform crop stand (Smith, 1988; Dieleman et al., 1995; Van Devender et al., 1997). In real field situations, weed infestations usually consist of several species present at various densities, and emerging at different times. Due to broadcast seeding, stands of irrigated rice in Latin America usually lack uniformity. Therefore, a function to predict yield losses must be driven by an independent variable capable of expressing the competitiveness of multispecies weed infestation in nonuniform rice stands. Simple density counts assign the same value to plants of different size or shape, failing to account for differences in their competitiveness. Coble and Mortensen (1992) sought to overcome this limitation by weighting the densities of individual species in mixed-weed infestations by a factor expressing their relative competitiveness. This factor was derived from single-weed additive experiments. A similar approach was applied to irrigated rice (Fischer and Ramirez, 1993). Simulation studies conducted with an ecophysiological model showed that the relative leaf area of weeds (leaf area of weeds as a proportion of the total leaf area) is more closely related to yield loss than is density count (Kropff and Spitters, 1991), and thus is likely to be a better descriptor of weed infestation levels.

The period between crop and weed emergence strongly affects weed competitiveness, and can be more critical than weed density in determining the need for postemergence weed control (Knezevic et al., 1993; Kropff, 1988). Modeling has also shown that differences in weed emergence dates can account for much of the seasonal variation in yield losses due to weed competition (Kropff and Lotz, 1993). Modifications of the basic density-yield loss hyperbola to account for the additional effect of the relative time of crop and weed emergence allowed to address this issue (Cousens et al., 1987; and Kropff and Spitters, 1991).

The objectives of this research were to (i) test existing empirical models to predict rice yield losses based on the early assessment of weed infestations; (ii) develop accurate estimators of the competitive potential of mixed-species weed infestations in irrigated rice; and (iii) assess how these empirical models and multi species weed competition descriptors can account for crop stand variations, and dates of weed emergence.

\section{MATERIALS AND METHODS}

Experiments were conducted at Palmira, Colombia $\left(3^{\circ} 30^{\prime}\right.$ $\mathrm{N}, 76^{\circ} 21^{\prime} \mathrm{W}, 1000 \mathrm{~m}$ elevation; mean growing temperature of $23.5^{\circ} \mathrm{C}$ ), on a fine-silty, mixed, isohyperthermic Aquic Hapludoll soil during two consecutive seasons (April-September 1993 and October-February 1994). Rice 'Oryzica 1' (indica type, $118 \mathrm{~d}$ to maturity) seed was broadcast over dry soil, and incorporated with a disk harrow. Nitrogen at $170, \mathrm{P}_{2} \mathrm{O}_{5}$ at 60 , and $\mathrm{K}_{2} \mathrm{O}$ at $36 \mathrm{~kg} \mathrm{ha}^{-1}$ were applied in the first season; $\mathrm{N}$ at
$220, \mathrm{P}_{2} \mathrm{O}_{5}$ at 60 , and $\mathrm{K}_{2} \mathrm{O}$ at $100 \mathrm{~kg} \mathrm{ha}^{-1}$ were applied in the second season.

The experimental layout sought to generate data for regression analysis from a wide range of infestations by various weed species emerging at different times and densities (no. plants per unit area) within heterogeneous rice stands. In the first season, an experiment was seeded (21 April) on a flat and uniform field ( 102 by $40 \mathrm{~m}$ ) divided into 15 plots ( 34 by $8 \mathrm{~m}$ ) representing random combinations of five rice seeding rates $\left(75,150,200,250\right.$, and $300 \mathrm{~kg}$ seed ha $\left.{ }^{-1}\right)$ with two weed emergence dates, which resulted from maintaining the crop weedfree during 15 or $30 \mathrm{DAE}$; a weed-free check was included. A similar experiment was seeded in the second season $(8$ October) with the same rice densities combined with one weed emergence date (24 DAE) and a weed-free check. A different weed emergence date was chosen for the second season, to test the applicability across seasons of the equations derived with data from the first season. The dates of weed emergence represent the times at which farmers usually make decisions for early, intermediate, and late postemergence herbicide applications. The crop densities were chosen to provide an environment with variable rice stands, and represent the range of rice densities usually found among rice farms. Within each plot, nine experimental units ( 4 by $3 \mathrm{~m}$ ) were selectively placed over uniform patches of weed infestation to represent the range of weediness in the plot. Weed-free periods were maintained by spraying weeds with quinclorac (3,7-dichloro-8-quinolinecarboxylic acid) at $0.38 \mathrm{~kg} \mathrm{ha}^{-1}$ and/or bentazon (3-(1methylethyl)-(1H)-2,1,3-benzothiadiazin-4(3H)-one 2,2-dioxide) at $1.2 \mathrm{~kg} \mathrm{ha}^{-1}$, as needed.

Weed emergence was monitored within six $0.09 \mathrm{~m}^{2}$ rectangles randomly placed in the plots. The number of stems, leaf area, and aboveground biomass of rice and weeds were recorded $2 \mathrm{wk}$ after the first weed seedlings appeared within a 0.5 -m-wide internal border of each experimental unit. At the same time, the ground covered by the aggregated weed canopies was visually estimated for the whole experimental unit, and expressed as percent of the total area covered by both crop and weed canopies. Rice grain yield (mathematically corrected to $140 \mathrm{~g} \mathrm{~kg}^{-1}$ moisture) was harvested from a $6-\mathrm{m}^{2}$ area within the experimental units.

Regression analysis was performed to relate rice yield losses to the observed levels of weed infestation. Four hyperbolic models were fitted to the data. The first model was proposed by Cousens (1985a):

$$
\mathrm{YL}=\frac{i D}{1+(i D / a)}
$$

where $\mathrm{YL}$ is percent yield loss, $D$ is weed density, $i$ is the percent yield lost to each additional weed when $D$ approaches zero, and $a$ is an asymptote corresponding to the maximum relative yield loss when $D$ tends to infinity. This model was later modified by Cousens et al. (1987) to account for the time between crop and weed emergence:

$$
\mathrm{YL}=\frac{b D}{e^{c t}+(b D / a)}
$$

where $t$ is relative time of weed and crop emergence, $b$ is the value of $i$ (Eq. [1]) when $t$ tends to zero, and $c$ is the rate at which $i$ decreases when $t$ increases towards infinity. The third model was also proposed by Cousens (1985b) to deal with both crop and weed densities:

$$
\mathrm{YL}=\frac{g f D}{1+d C+f D}
$$


where $C$ is crop density, and $d, f$, and $g$ are empirical nonlinear parameters. The last model is another hyperbola recently proposed by Kropff and Lotz (1993):

$$
\mathrm{YL}=\frac{q D}{1+[(q / a)-1] D}
$$

where the independent variable $D$ ( $L$ in the original equation) is the weed relative area or weed leaf area as a fraction of the total (crop + weed) leaf area, $q$ is the slope of the hyperbola or relative damage coefficient (Kropff and Spitters, 1991), and $a$ is the asymptote for maximum yield loss. The equations above, and their parameters, were estimated by nonlinear regression using the curve-fitting module of the SigmaPlot software (Jandel Scientific, San Rafael, CA).

Different independent variables were used with the above models to describe multispecies weed infestation levels: density $(D)$, leaf area index (LAI), biomass $\mathrm{m}^{-2}(B)$, relative density [weed/(crop + weed)], relative leaf area (RLA), and a visual estimation of the area covered by the vertical projection of the weed foliage as a fraction of the total area covered by both the weed and the crop foliage $\left(\mathrm{RC}_{\mathrm{v}}\right)$.

Goodness of fit of the regressions was assessed from the mean square errors and $r^{2}$-values. Differences between regressions for early and late weed emergence, and for first vs. second seasons were analyzed using the $F$-test proposed by Chow (1960). For this test, a regression was fit to the data combined for two emergence dates, thus a residual sum of squares $\left(S_{1}\right)$ was obtained with $n_{1}+n_{2}-k$ degrees of freedom, where $n$ is the number of observations and $k$ is the number of estimated parameters. Following, sums of squares $S_{2}$ and $S_{3}$, (with $n_{1}-k$ and $n_{2}-k$ df, respectively) were obtained from two separate regressions calculated for each emergence date. Lastly, $S_{4}=S_{2}+S_{3}$, with df $=n_{1}+n_{2}-2 k$, and $S_{5}=S_{1}-S_{4}$ were obtained, and the following $F$-statistic was calculated:

$$
F=\frac{S_{5} / k}{S_{4} /\left(n_{1}+n_{2}-2 k\right)}
$$

with $k$ and $n_{1}+n_{2}-2 k$ degrees of freedom. When the computed $F$ exceeded the critical value, the hypothesis that both sets of data could be described by a single regression line was rejected.

\section{RESULTS AND DISCUSSION}

\section{Dynamics of Weed Emergence, and Yield Loss}

Weed populations consisted mostly of grasses, sedges, and one broadleaf species (Table 1). Most weeds emerged at 15 and $30 \mathrm{DAE}$ in the first season, and at 24 DAE in the second season (Table 2). Weed infestations were assessed $15 \mathrm{~d}$ after the peak of emergence; an earlier assessment would have missed a significant portion of the final infestation (Table 2), while later assess-
Table 1. Average dry matter of 15 -d-old weeds emerging at different dates after rice emergence (DAE) in two consecutive grow-

\begin{tabular}{|c|c|c|c|}
\hline \multirow[b]{3}{*}{ Weed species } & \multicolumn{3}{|c|}{ Weed dry matter } \\
\hline & \multicolumn{2}{|c|}{ Season 1} & \multirow{2}{*}{$\frac{\text { Season } 2}{24 \text { DAE }}$} \\
\hline & 15 DAE & 30 DAE & \\
\hline & & $\mathbf{g ~ m}^{-2}$ & \\
\hline $\begin{array}{l}\text { junglerice [Echinochloa colona (L.) } \\
\text { Link] (Poaceae) }\end{array}$ & $10.4(2.8) \dagger$ & $0.5(0.2)$ & $17.3(2.3)$ \\
\hline $\begin{array}{l}\text { goosegrass [Eleusine indica (L.) } \\
\text { Gaertn.] (Poaceae) }\end{array}$ & $3.7(1.0)$ & $15.9(3.4)$ & $1.3(0.3)$ \\
\hline $\begin{array}{l}\text { purple nut sedge (Cyperus rotundus L.) } \\
\text { (Cyperaceae) }\end{array}$ & $3.9(0.4)$ & $8.3(2.0)$ & $6.2(1.5)$ \\
\hline $\begin{array}{l}\text { fingergrass (Chloris dandyana C.D. } \\
\text { Adams) (Poaceae) }\end{array}$ & $0.7(0.2)$ & $8.7(2.9)$ & $0.1(0.0)$ \\
\hline $\begin{array}{l}\text { eclipta [Eclipta prostrata (L.) L.] } \\
\text { (Asteraceae) }\end{array}$ & $0.2(0.1)$ & $0.1(0.1)$ & $0.6(0.1)$ \\
\hline $\begin{array}{l}\text { johnsongrass [Sorghum halepense (L.) } \\
\text { Pers.] (Poaceae) }\end{array}$ & $0.2(0.1)$ & $0.7(0.3)$ & $0.3(0.1)$ \\
\hline Total & $3.2(0.6)$ & $5.7(0.9)$ & $4.3(0.6)$ \\
\hline
\end{tabular}
ing seasons in Palmira, Colombia.

$\dagger$ Values in parenthesis are standard errors of the means.

ments would have encountered both weeds too large to be practically controlled and late-emerging ( $\geq 30 \mathrm{DAE})$ seedlings with only minor effect on yields (Fig. 1). Nevertheless, late postemergence herbicide applications are often applied in response to similar weed emergence patterns.

\section{Descriptors of Weed Infestation and Crop Stand}

Of the different independent variables tested, $D$ related poorly to the effects of weed competition, resulting in regressions with high mean square errors and low $r^{2}$ (Table 3). Thus, weed counts resolved poorly the strong yield loss differences observed when weeds emerged at two different times (Fig. 1). Other studies have also noted that weed counts fail to reveal differences in competitiveness among plants with different sizes and morphologies that emerge at different times (Parker and Murdoch, 1996; Kropff and Lotz, 1993). Better predictions were obtained with descriptors closely related to the effects of competition, such as weed LAI and $B$. Even better regressions resulted when RLA, and $\mathrm{RC}_{\mathrm{v}}$ were used as independent variables (Table 3). By expressing the relative apportionment of light between rice and the weeds, these descriptors adequately resolved the differences in yield loss resulting from weeds that emerged at different times (Table 4). Light was thus a key resource regulating rice-weed interactions in this irrigated system.

$\mathrm{RC}_{\mathrm{v}}$ expresses essentially the same information as RLA, and is easier to estimate in the field. Also, by

Table 2. Weed seedlings emerging at different dates after rice emergence (DAE) when rice was kept weed-free for different periods

\begin{tabular}{|c|c|c|c|c|c|c|c|c|}
\hline \multirow[b]{2}{*}{ Season } & \multirow{2}{*}{$\begin{array}{c}\text { Weed-free } \\
\text { period }\end{array}$} & \multicolumn{7}{|c|}{ Weed emergence } \\
\hline & & 15 DAE & 24 DAE & 30 DAE & 37 DAE & 44 DAE & 51 DAE & 59 DAE \\
\hline & d & & & & - no. $\mathbf{m}^{-2}$ & & & 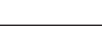 \\
\hline 1 & $\begin{array}{l}15 \\
30\end{array}$ & $\begin{array}{c}18(7) \dagger \\
-\end{array}$ & $\begin{array}{c}37 \text { (12) } \\
-\end{array}$ & $\begin{array}{l}17(6) \\
17(16)\end{array}$ & $\begin{array}{l}15 \text { ( 6) } \\
46(44)\end{array}$ & $\begin{array}{r}7(2) \\
25(24)\end{array}$ & $\begin{array}{r}7(2) \\
13(13)\end{array}$ & - \\
\hline 2 & 24 & - & $340(40)$ & $574(68)$ & 353 (43) & 226 (32) & $49(6)$ & $36(4)$ \\
\hline
\end{tabular}
after emergence in two consecutive seasons at Palmira, Colombia.

$\dagger$ Values in parenthesis are standard deviations of the means. 
integrating the whole plot area in the mind of the observer, $\mathrm{RC}_{\mathrm{v}}$ may have contributed to reducing sampling error. Also, visual ratings of cover involve almost inevitably a subjective estimation of size or volume, which correlates with competitiveness (Bussler et al., 1995). Thus, the best yield loss predictions based on a single independent variable were obtained by describing mixed-weed infestations in terms of $\mathrm{RC}_{\mathrm{v}}$ (Table 3 ). However, $\mathrm{RC}_{\mathrm{v}}$ estimates are subjective, and may limit the range of users, but objective cover estimates can be obtained from photographic analysis (Lutman et al., 1996) or, in the near future, with advanced digital imaging technology.

Although good predictions were obtained with a single independent variable representing the aggregate effect of all species, species with contrasting morphological and physiological traits may be best dealt with individually (Fischer and Ramirez, 1993; Kropff and Lotz, 1993; Parker and Murdoch, 1996). Thus, predictions based on the aggregate RLA of weeds were further improved when the RLA of each major species in the weed mixture was recorded separately, and their effect on yield loss considered additively:
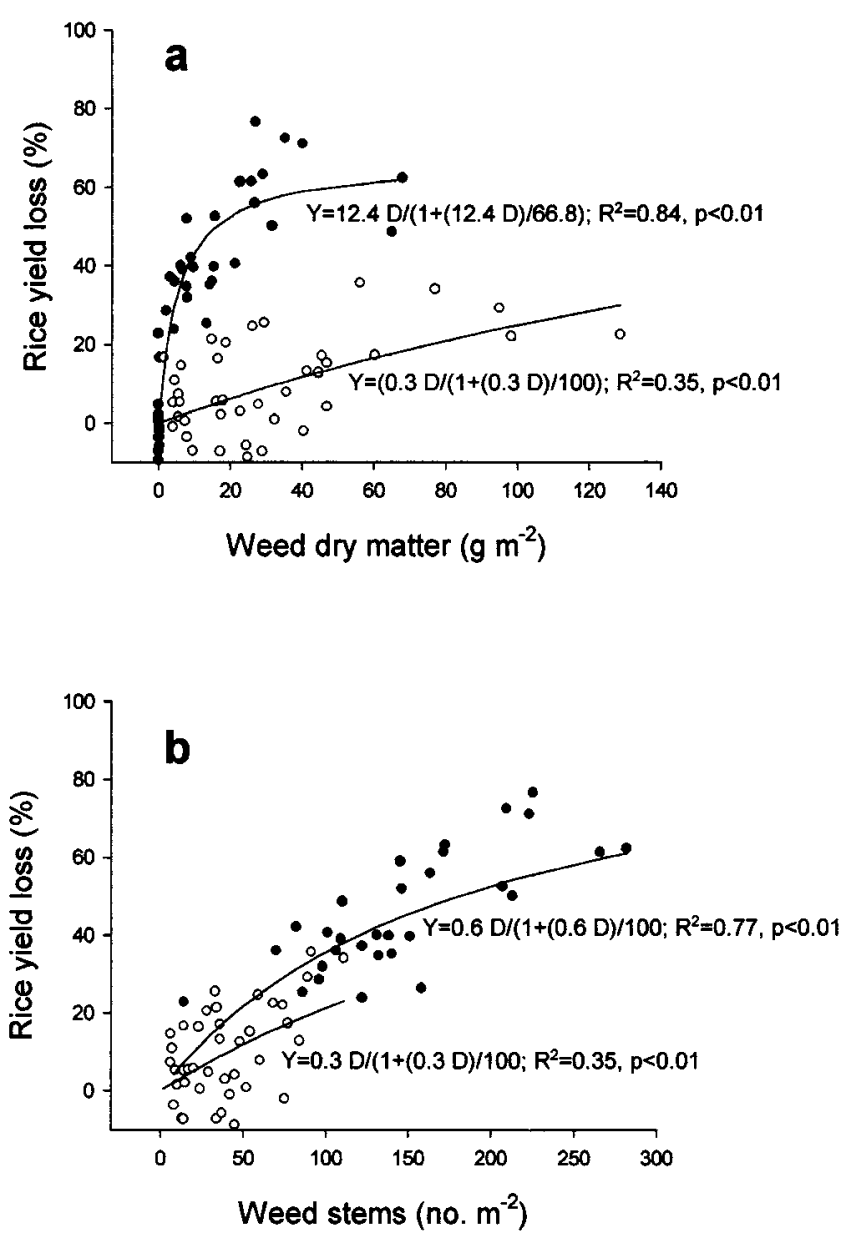

Fig. 1. Rice yield losses resulting from weeds emerging at 15 (solid symbols) and 30 (open symbols) DAE as predicted by Model [1] with (a) weed dry matter or (b) stem density as independent variables.

$$
\mathrm{YL}=\sum \frac{i_{n} \mathrm{RLA}_{n}}{1+\left(i_{n} \mathrm{RLA}_{n} / a_{n}\right)}
$$

where $n$ corresponds to the effect of the $n$th weed species, and $\mathrm{RLA}_{n}$ is its relative leaf area. This approach reduced the mean square errors of the regressions obtained with Eq. [1] and RLA or $\mathrm{RC}_{\mathrm{v}}$ as single independent variables (Table 3 ) by 36 and $23 \%$, respectively.

Broadcast seeding of irrigated rice in the tropics often results in poor stand uniformity, and farmers use various seeding rates to resist weed competition (Fischer and Ramirez, 1993). Therefore, a practical yield loss prediction approach must account for variable stands within and between farms. One such approach could be the use of a yield loss model incorporating crop density as an additional independent variable (Model 3). However, this modification did not improve our predictions when RLA or $\mathrm{RC}_{\mathrm{v}}$ were used as independent variables (Table 3), suggesting that these descriptors were already accounting satisfactorily for the various rice seeding rates in our experiment.

\section{Time of Crop and Weed Emergence}

All models described similarly well the hyperbolic relationships between yield losses and weed infestation (Fig. 1 and Table 3), with plots of residuals against predicted yields indicating homogeneous variances (data not shown). Each of the three weed emergence events had a distinct effect on rice yield losses (Table 4) according to an $F$-test (Chow, 1960) applied to compare regressions. In the first season, when weeds emerged at 15 DAE, rice yield losses were much larger than those resulting from weeds emerging $15 \mathrm{~d}$ later (Fig. 1). In the second season, when weeds emerged at 24 DAE, yield losses were intermediate with respect to those in the first season (Fig. 2).

The time between crop and weed emergence has been widely recognized as a key factor regulating weed-crop interference (Cousens et al., 1987; Kropff and Lotz, 1993; Knezevic et al., 1993). The need to incorporate this factor in predicting yield losses is relevant to many rice fields in Latin America, where weeds often emerge in successive flushes until late in the growing season. Thus, a hyperbola (Eq. [3]) with an additional term accounting for the period between crop and weed emergence, and $\mathrm{RC}_{\mathrm{v}}$ as independent variable, was fitted to data from the first season. Competition losses occurring in two seasons, following three dates of weed emergence, were predicted by making $t$ in Eq. [3] equal to the number of days between crop and weed emergence (Fig. 2). This was indeed a simplified use of this model, which for better accuracy should be fitted to a database with more weed emergence times, but the potential of this single relationship to describe effects resulting of complex weed mixtures and emergence patterns is clearly illustrated. This exercise also demonstrates the relevance of the period between crop and weed emergence as a major source of variation between seasons, notably in Colombia, where irrigated rice grows in relatively stable environments and where weather parameters change only moderately over seasons. 
Table 3. Mean square errors (MSE) of regressions fit to data from different periods of weed emergence (in terms of days after rice emergence, DAE), using three different yield loss prediction models and various descriptors $(D)$ of multispecies weed infestation as independent variables.

\begin{tabular}{|c|c|c|c|c|c|c|c|c|}
\hline \multirow[b]{2}{*}{ Season } & \multirow[b]{2}{*}{ DAE } & \multirow[b]{2}{*}{$D$} & \multicolumn{2}{|c|}{ Model 1 (Eq.) [1] } & \multicolumn{2}{|c|}{ Model 3 (Eq. [3]) } & \multicolumn{2}{|c|}{ Model 4 (Eq. [4]) } \\
\hline & & & MSE & $r^{2}$ & MSE & $r^{2}$ & MSE & $r^{2}$ \\
\hline \multirow[t]{14}{*}{1} & 15 & Density & 140 & 0.77 & 135 & 0.77 & 152 & 0.74 \\
\hline & & Relative density & 179 & 0.70 & 179 & 0.70 & 220 & 0.63 \\
\hline & & Leaf area & 98 & 0.85 & 185 & 0.72 & 92 & 0.86 \\
\hline & & Relative leaf area & 90 & 0.86 & 90 & 0.86 & 90 & 0.86 \\
\hline & & Biomass & 102 & 0.84 & 140 & 0.78 & 102 & 0.84 \\
\hline & & Relative biomass & 160 & 0.75 & 160 & 0.75 & 160 & 0.75 \\
\hline & & Relative cover & 72 & 0.90 & 72 & 0.90 & 72 & 0.90 \\
\hline & 30 & Density & 121 & 0.35 & 165 & 0.16 & 125 & 0.33 \\
\hline & & Relative density & 115 & 0.38 & 117 & 0.37 & 124 & 0.33 \\
\hline & & Leaf area & 118 & 0.36 & 103 & 0.45 & 118 & 0.36 \\
\hline & & Relative leaf area & 94 & 0.46 & 105 & 0.43 & 104 & 0.44 \\
\hline & & Biomass & 121 & 0.35 & 114 & 0.37 & 121 & 0.35 \\
\hline & & Relative biomass & 105 & 0.43 & 113 & 0.39 & 105 & 0.43 \\
\hline & & Relative cover & 62 & 0.59 & 62 & 0.59 & 62 & 0.59 \\
\hline \multirow[t]{7}{*}{2} & 24 & Density & 227 & 0.44 & 204 & 0.50 & 210 & 0.48 \\
\hline & & Relative density & 244 & 0.40 & 187 & 0.54 & 188 & 0.54 \\
\hline & & Leaf area & 214 & 0.46 & 218 & 0.42 & 190 & 0.52 \\
\hline & & Relative leaf area & 150 & 0.55 & 163 & 0.59 & 163 & 0.59 \\
\hline & & Biomass & 197 & 0.51 & 199 & 0.48 & 197 & 0.51 \\
\hline & & Relative biomass & 166 & 0.58 & 166 & 0.58 & 166 & 0.58 \\
\hline & & Relative cover & 90 & 0.69 & 90 & 0.70 & 92 & 0.69 \\
\hline
\end{tabular}

$\dagger$ Model 1: Yield YL $=i D /[1+(i D / a)]$. Model 3: YL $=g f D /(1+d C+f D)$. Model 4: $\mathrm{YL}=q D /[1+(q / a-1) D]$. See text for full presentation of the equations.

\section{CONCLUSIONS}

Realistic hyperbolic yield loss models, driven by variables describing the competitiveness of multispecies weed infestations, allow for the economic analysis of weed management options. These models can also be used to define economic thresholds of weed infestation, but their usefulness often faces concerns about longterm effects, such as the build-up of weed seed in the soil (Bauer and Mortensen, 1992), or the propagation of herbicide resistant weeds when subthreshold infestations are not controlled. Although the magnitude of the seed rain on most irrigated rice fields in tropical Latin America (and likewise the paramount need for reducing herbicide use) may perhaps outweigh such concerns, the usefulness of yield loss prediction as a component of decision-support systems goes beyond the judging of whether or not to spray. Instead, this approach should guide the selection of economic alternatives to the excessive use of herbicides, thus preventing the development of herbicide resistance in weeds, high production

Table 4. Comparison $\dagger$ of regressions using Model 2 (Eq. [2] in text) fitted for different weed emergence times. A significant $F$-value suggests that the data set is best described by two independent regressions, one for each weed emergence time.

\begin{tabular}{|c|c|c|c|c|}
\hline Independent variable & $\begin{array}{c}\text { Time of weed } \\
\text { emergence } \\
\text { (DAE) } \%\end{array}$ & $\begin{array}{c}\text { Residual sums } \\
\text { of squares }\end{array}$ & df & $F_{(2 / d f)}$ \\
\hline Relative cover & $\begin{array}{l}15 \text { vs. } 30 \\
15 \text { vs. } 24 \\
24 \text { vs. } 30\end{array}$ & $\begin{array}{r}12752 \\
13037 \\
6877\end{array}$ & $\begin{array}{l}79 \\
81 \\
84\end{array}$ & $\begin{array}{c}\mathbf{5 5 . 9} \mathbf{9}^{* *} \\
\mathbf{3 9 . 4}^{* *} \\
\mathbf{3 . 2}^{*}\end{array}$ \\
\hline Relative leaf area & $\begin{array}{l}15 \text { vs. } 30 \\
15 \text { vs. } 24 \\
24 \text { vs. } 30\end{array}$ & $\begin{array}{l}30207 \\
33842 \\
15265\end{array}$ & $\begin{array}{l}80 \\
85 \\
89\end{array}$ & $\begin{array}{r}124.5^{* * *} \\
\mathbf{6 6 . 8} \text { *** } \\
5.2^{* *}\end{array}$ \\
\hline
\end{tabular}

**** Significant at the 0.05 and 0.01 probability levels, respectively.

$\dagger$ Chow, G.C. 1960. Tests of equality between sets of coefficients in two linear regressions. Econometrica 28:591-605.

$\$$ Weed emergence at 15 or $30 \mathrm{~d}$ after rice emergence (DAE) in Season 1 , and at 24 DAE in Season 2. costs, injury to surrounding crops, and possible human and environmental hazards.

Due to site-to-site variation, yield loss predictions using empirical equations cannot be extrapolated widely across different locations. Thus, the equations presented in this study are not intended for extrapolation over the entire rice area of Colombia. Rather, they represent a conceptual approach, which suggests that the range of prediction with empirical models could be expanded by detecting and incorporating into the yield loss algorithm key sources of variation between sites or seasons. Fur-

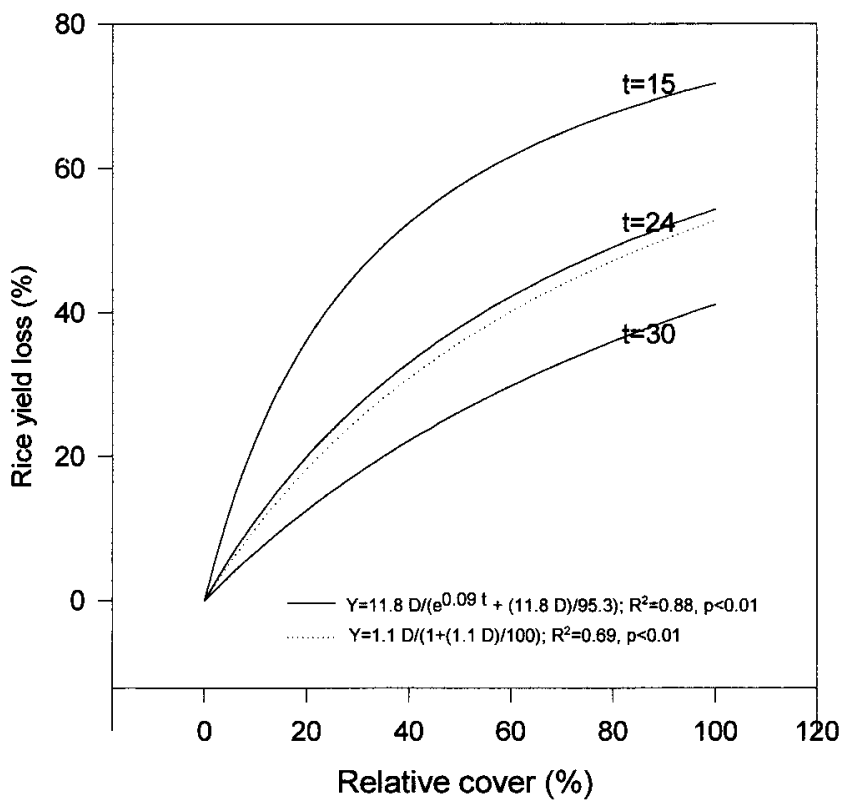

Fig. 2. Rice yield losses predicted with Model [2] with $t=15,24$ and 30 DAE (solid lines) fitted to data from the first season (weeds emerged at 15 and $30 \mathrm{DAE}$ ), compared with yield losses predicted with Model [1] (broken line) fitted to data from the second season when weeds emerged at 24 DAE. 
ther experimentation conducted over multiple locations and seasons is needed to establish the range of extrapolability of prediction models derived following this approach. Models accounting for the time of weed emergence, and using competition-related independent variables, should be helpful in dealing with at least some seasonal effects, and may also reach a wider range of users than do the more complex to use ecophysiological models.

Describing the competitiveness of multispecies weed infestations with a single variable implies that rice and weeds must have similar growth rates, for their relative light interception to be the same from the time it is first recorded until canopy closure and full light interception. However, the morphological and physiological diversity of weeds may justify treating species individually, and incorporating their effect additively into a hyperbolic model.

\section{REFERENCES}

Bauer, T.A., and D.A. Mortensen. 1992. A comparison of economic and economic optimum thresholds for two annual weeds in soybeans. Weed Technol. 6:228-235.

Bussler, B.H., B.D. Maxwell, and K.J. Puettmann. 1995. Using plant volume to quantify interference in corn (Zea mays) neighborhoods. Weed Sci. 43:586-594.

Chow, G.C. 1960. Tests of equality between sets of coefficients in two linear regressions. Econometrica 28:591-605.

Coble, H., and D.A. Mortensen. 1992. The threshold concept and its application to weed science. Weed Technol. 6:191-195.

Cousens, R. 1985a. A simple model relating yield loss to weed density. Ann. Appl. Biol. 107:239-252.

Cousens, R. 1985b. An empirical model relating crop yield to weed and crop density, and a statistical comparison with other models. J. Agric. Sci. 105:513-521.

Cousens R., P. Brain, J.T. O'Donovan, and A. O'Sullivan. 1987. The use of biologically realistic equations to describe the effects of weed density and relative time of emergence on crop yield. Weed Sci. 35:720-725.

Dieleman, A., A.S. Hamill, S.F. Wiese, and C.J. Swanton. 1995. Empirical models of pigweed (Amaranthus spp.) interference in soybean (Glycine max). Weed Sci. 43:612-618.

Fischer, A.J., E. Granados, and D. Trujillo. 1993. Propanil resistance in populations of junglerice (Echinochloa colona) in Colombian rice fields. Weed Sci. 41:201-206.

Fischer, A., and H. Ramirez. 1993. Mixed-weed infestations: Predictions of crop losses for economic weed management in rice. Int J. Pest Manage. 39:354-357.

Food and Agricultural Organization (FAO). 1997. FAOSTAT statistics database [Online]. Available at http://apps.fao.org (verified 9 Feb. 1998).

Knezevic, S., C.J. Swanton, and S.F. Wiese. 1993. Threshold of redroot pigweed (Amaranthus retroflexus L.) in corn. p. 53. In WSSA Abstracts 33 (Denver, CO). WSSA, Champaign, IL.

Kropff, M.J. 1988. Modeling the effects of weeds on crop production. Weed Res. 28:465-471.

Kropff, M.J. 1993. Eco-physiological models for crop-weed competition. p. 25-32. In M.J. Kropff and H.H. van Laar (ed.) Modeling crop-weed interactions. CAB Int., Wallingford, UK

Kropff, M.J., and L.A.P. Lotz. 1993. Empirical models for crop-weed competition. p. 9-24. In M.J. Kropff and H.H. van Laar (ed.) Modeling crop-weed interactions. CAB Int., Wallingford, UK.

Kropff, M.J., and C.J.T. Spitters. 1991. A simple model of crop loss by weed competition from early observations on relative leaf area of the weeds. Weed Res. 31:97-105.

Kwon, T.J., D.L. Young, F.L. Young, and C.M. Boerboom. 1995. PALWEED: WHEAT: A bioeconomic model for postemergence weed management in winter wheat (Triticum aestivum). Weed Sci. 43:595-603.

Lutman, P.J.W., R. Risiott, and P. Osterman. 1996. Investigations into alternative methods to predict the competitive effects of weeds on crop yields. Weed Sci. 44:290-297.

Lybecker, D.W., E.E. Schweitzer, and R.P. King. 1991. Weed management decisions in corn based on bioeconomic modeling. Weed Sci. 39:124-129.

Parker, L., and A.J. Murdoch. 1996. Mathematical modeling of multispecies weed competition in wheat. p. 153-158. In Int. Weed Control Congr., 2nd, Copenhagen. 25-28 June 1996. Dep. of Weed Control and Pesticide Ecology Flakkebjerg, Denmark.

Smith, R.J., Jr. 1988. Weed thresholds in Southern U.S. rice, Oryza sativa. Weed Technol. 2:232-241.

Valverde, B.E. 1996. Management of herbicide resistant weeds in Latin America: The case of propanil-resistant Echinochloa colona in rice. p. 415-420. In Int. Weed Control Congr., 2nd, Copenhagen. 25-28 June 1996. Dep. of Weed Control and Pesticide Ecology, Flakkebjerg, Denmark.

Van Devender, K.W., T.A. Costello, and R.J. Smith, Jr. 1997. Model of rice (Oryza sativa) yield reduction as a function of weed interference. Weed Sci. 45:218-224.

Wilkerson, G.G., S.A. Modena, and H.D. Coble. 1991. HERB: Decision model for postemergence weed control in soybeans. Agron. J. 83:413-417.

\section{Reprinted with permission from the American Society of Agronomy. Originally published in Agronomy Journal 91(1):87-92, Copyright 1999.}

